\title{
Conducting A Real-Time Instrument System for Observing Biogas Digester's Temperature and Humidity
}

\author{
Meta Yantidewi, Nurita Apridiana Lestari, and Utama Alan Deta \\ Department of Physics, Faculty of Mathematics and Natural Sciences, Universitas Negeri Surabaya, C3 Building, \\ Ketintang, Surabaya 60231, Indonesia \\ metayantidewi@unesa.ac.id
}

\begin{abstract}
Biogas is a clean and renewable energy generated from organic digestion under anaerobic condition. The anaerobic process is held inside a biogas digester. The production of biogas in a biogas digester might be affected by the temperature degree and humidity of the digester. This research focused on building a real-time instrument system for observing the temperature and humidity in a biogas digester. The system was mainly consisted of biogas digester acquisition system and the observation of its application system. The temperature and humidity data captured from the biogas digester were shown in the form of tables and charts through the observation system. In general, it can be said that the real-time instrument system built in this research had an ability to observe and measure the temperature and humidity in biogas digester. Thus, the real-time instrument system could be utilized as a viable and easy alternative instrument for the monitoring/observation of anaerobic digestion in biogas production.
\end{abstract}

Keywords- Real-time instrument system, biogas digester, temperature, humidity.

\section{INTRODUCTION}

Anaerobic digestion is a biochemical process that converts various organic materials into biogas using oxygen-free microorganisms naturally $[1,2]$. In addition to producing biogas, anaerobic digestion process also produces a liquid effluent (called digestate) containing all water, all minerals, and about half of the carbon derived from the incoming material. Anaerobic digestion process in biogas production generally takes place in the digestive tank or better known as biogas digester.

However, some parameters might affect the process. Sambo et al [3], in their study, found that temperature had significant effect and temperature degree which exceeded 60 degrees causing the gas production gradually decreased and eventually stopped. Vindis et al in Prasad also says that, in anaerobic digestion, the steadiness of temperature was important [4]. Moreover, Gu et al, as cited in Panjaitan et al, states that temperature and humidity play an important role in the anaerobic digestion process of biogas [5]. According to Labatut and Gooch, digester temperature should be always maintained between $35^{\circ} \mathrm{C}\left(95^{\circ} \mathrm{F}\right)$ and $40^{\circ} \mathrm{C}\left(105^{\circ} \mathrm{F}\right)$ [6]. Doing operation at temperatures beyond the normal range will result in the decrease of biogas production and organic matter stabilization. In addition, the long periods of time under these conditions might eventually stop biogas production and cause digester failure. Furthermore, the process would be generally influential at higher temperatures than at lower ones [6]. The appropriate and correct design of the system parameters is essential to maximise efficiency process, increase stability, and prevent system failure [6]

This research aimed at presenting an instrument system for observing the temperature and humidity percentage in a biogas digester. The instrument system used in this study would observe the temperature and humidity inside the biogas digester in real-time in order to ensure that no interference occured in the biogas digester during the anaerobic digestion process. Observing those affecting parameters using a realtime instrument system would become a benefit.

\section{MATERIAL AND METHOD}

A real-time instrument system is defined as a system that responds toward the transactions done by immediately updating and/or generating a response in a time frame which is fast enough to keep an operation moving at its required speed. In the process of data acquisition, a physical phenomenon is received and transformed into electrical signal. By then, the signal is measured and converted into digital format through analysing, processing, and saving carried out by a computer [7]. In some applications, the data acquisition system is used not only to acquire data or information, but also to control visualization, storage, processing, and analysing $[8,9,10]$.

The real-time instrument system in this research was mainly constructed of the biogas digester acquisition system 
and its observation system done by the user through the application software. A data acquisition system (DAS), or better known as acquisition system, is a system that is used to retrieve, collect, and prepare data in order to process it into the expected data [11]. The components of the data acquisition system include sensors that convert a measurement parameter into an electrical signal which is then received by the data acquisition hardware. The data obtained is usually displayed, analysed and stored on a personal computer (PC).

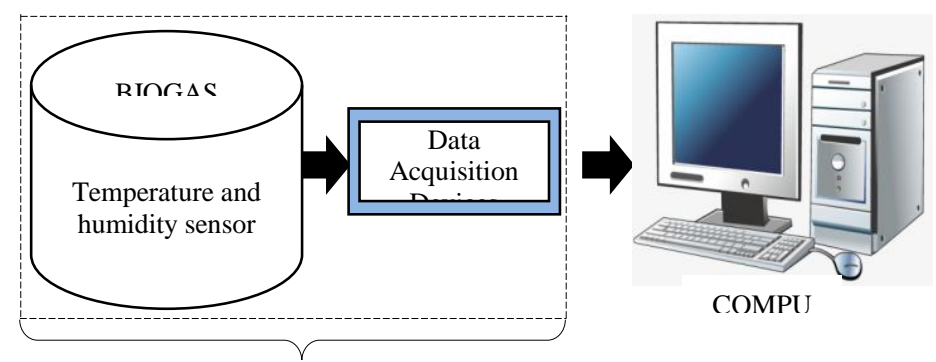

Biogas Digester Acquisition System

Figure 1: The block diagram of the real-time instrument system.

As can be seen in Figure 1, the biogas digester acquisition system was composed of biogas digester, sensors system, and data acquisition devices. The biogas digester here was in the form of mini-scale or laboratory-scale digester, while the system sensors used in the research were temperature and humidity sensor. The information sensor was then acquired by the data acquisition devices. All processing of temperature and humidity data inside the biogas digester became the data acquisition devices' responsibility. The data acquisition devices subsequently passed the processed data into the computer. The computer acted as an information viewer system which was based on the temperature and humidity inside the biogas digester.

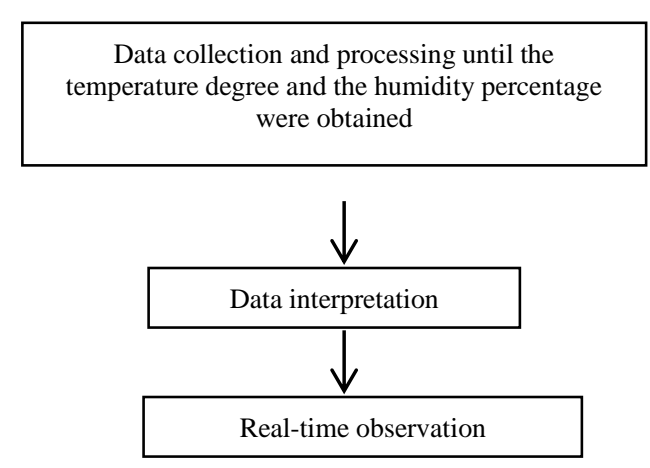

Figure 2: The procedure of a real-time instrument system for observing temperature and humidity inside the biogas digester

The procedure of the real-time instrument system for observing the temperature and humidity inside biogas digester is shown in Figure 2 above. The temperature degree and humidity percentage were detected by the temperature and humidity system sensors which were then being interpreted by the data acquisition devices to be presented on PC

\section{RESULTS AND DISCUSSION}

\section{A. Biogas digester acquisition system}

The temperature and humidity inside the biogas digester were detected by a single chip multi-sensor SHT11 which was comprised of calibrated digital output. Therefore, it needs no calibration. The measured humidity here was relative humidity. It was different from absolute humidity since absolute humidity was the measure of water vapor in the air. Regardless of the temperature, a relative humidity was the amount of water vapor in the air shown by the percentage of the total amount which was able to be carried out in its current temperature. SHT11 has already been a built-in analog-todigital (ADC) and conditioning signal circuit. Therefore, it needs no more ADC and conditioning signal circuit. In addition, SHT11 could be connected directly to any microcontroller by means of the 2 -wire digital interface. The aforementioned sensor received a converted command from microcontroller in order to start measuring the temperature and humidity. The measurement commands for the temperature and humidity were 0000011 and 00000101 respectively. After receiving commands from microcontroller, the sensor issued an acknowledge pulse by pulling the DATA line into low position for one clock cycle. The DATA was a bidirectional data transferring pin in SHT11 in order to send the data in and out of the sensosr. On the other hand, after giving those commands, the microcontroller had to wait for a complete measurement. During the waiting time and complete measurement, the microcontroller stopped generating clocks on SCK line and release the DATA line. Meanwhile, the sensor generated a Data Ready signal by pulling the DATA line low. Th SCK was the clock line that was used to synchronize the communication between the microcontroller and SHT11.

The biogas digester acquisition system only required a microcontroller as its data acquisition device. The microcontroller received data from the sensors which was then sent to the computer in a serial way. The configuration of reception and the delivery between the microcontroller and the computer were adjusted afterwards. The serial delivery speed was 9600 bits per second. Furthermore, the data transmission was received by the computer serial communication receivers and then processed by Delphi in the real time.

\section{B. Observation system}

The information viewer system showed the information of temperature and humidity in the biogas digester during the anaerobic digestion process. The viewer system used Delphi 
as its application software. Delphi was selected because it is user friendly for the beginner programmer. Moreover, it has various components, fast compilation speed which makes it easier to modify, and also the ease of creating User Interface $[12,13]$.

Figure 3 below presents a user login page as the initial display page before entering the main observation page. This page was created as a login key and a way to prevent data misapplication.

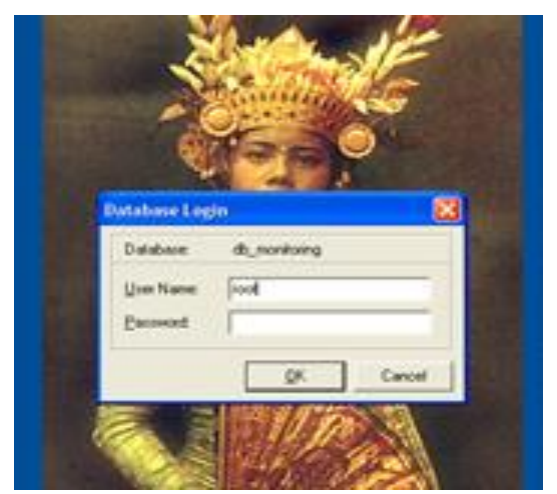

Figure 3: User login page in the instrument system.

After being succeeded in entering the user login page, the next display was the main observation page. In this page, the information of temperature and humidity in biogas digester which was gathered by SHT11 in this research are shown in Figure 4.

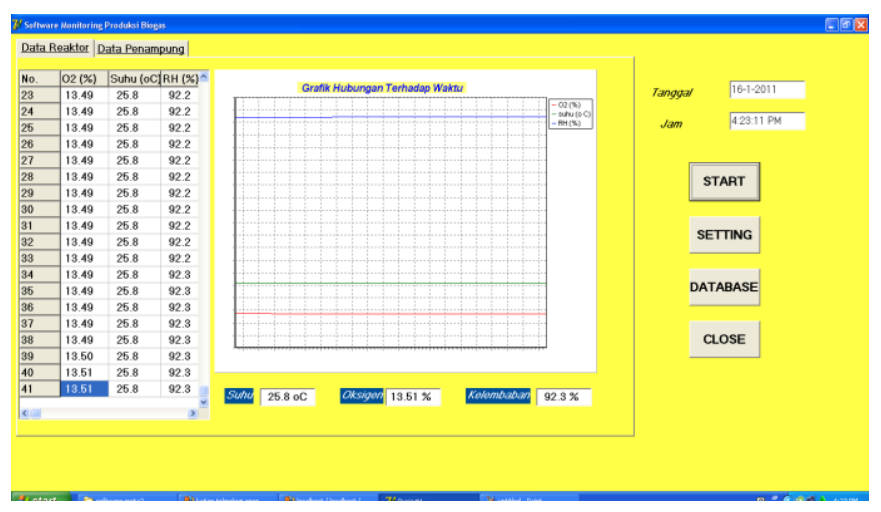

Figure 4: The information of the temperature and humidity in biogas digester displayed by the viewer system.

The temperature and humidity information were displayed in the forms of line graphs and tables. The temperature was stated in Celcius degree and the humidity was in the form of percentage. Four buttons were found in the observation system as seen in Figure 4. The followings are some short descriptions about the buttons.

\section{1) START/STOP button.}

At the beginning of measuring the temperature and humidity, a START button would appear. This button was used to begin the measurement and recording process from the sensor into observation system. If the button was clicked once again, the measurement and the recording process would stop.

\section{2) SETTING button.}

This button contained an initial setting of serial port from the microcontroller to the computer. If the button was deactivated, the connection between the microcontroller serial port and the computer serial port would disconnected.

\section{3) DATABASE button.}

This button was the access key to the database page.

\section{4) CLOSE button}

This last button was meant to end the observation system. When the CLOSE button was clicked, a dialogue box, shown in Figure 4, asking if the user really wants to end and close the system, would appear.

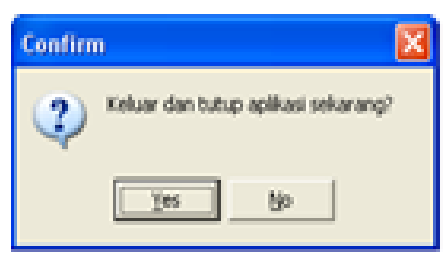

Figure 5: A dialogue box appeared when the CLOSE button is clicked.

Because the system built was a real-time system, then it was also capable of displaying the temperature and humidity percentage in accordance with the searching date.

\section{CONCLUSION}

The instrument system in this research was mainly constructed of biogas digester acquisition system and the observation system. In addition, the system built through this study could observe the temperature degree and the humidity percentage in the real time. Furthermore, the observation system used Delphi as its application platform due to its complete and facilitating elements.

\section{REFERENCES}

[1] D. Botheju and Bakke, "Oxygen Effects in Anaerobic Digestion - A Review", Open Waste Management J., vol. 4, no. 1, 2011.

[2] Q. Zhang, J. Hu, and D-J. Lee, "Biogas from anaerobic digestion processes: research updates", Renewable Energy, vol. 98, no. 108, pp. 108-119, 2016.

[3] A. S. Sambo, B. Garba, and B. G. Danshehu, "Effect of some operating parameters on biogas production rate", Renewable Energy, vol. 6, no. 3, p. 343, 1995.

[4] R. D. Prasad, "Empirical Study on Factors Affecting Biogas Production", ISRN Renewable Energy, vol. 1, 2012.

[5] S. D. Panjaitan, N. Fratama, A. Hartoyo, and R. Kurnianto, "Telemonitoring Temperature and Humidity at Bio-energy Process using Smart Phones", Telkomnika, vol. 14, no. 2, p. 762, 2016 
[6] R. A. Labatut and C. A. Gooch, Proc. of Got Manure? Enhancing Environmental and Economic Sustainability, New York, 2012, p 209

[7] P. F. S. Teixeira, L. F. Moura, S. W. S. Lima, D. Albiero, F. A. Gondinu and A. R. de Alexandria, J. Sustainable Bioenergy Sys., vol. 7, no. 117, 2017.

[8] J. Park and S. Mackay, Practical Data Acquisition for Instrumentation and Control System, Amsterdam: Elsevier Science, 2003.

[9] T. M. McPhillips, S. E. McPhillips, H-J. Chiu, A. E. Cohen, A. M. Deacon, P. J. Ellis, E. Garman, A. Gonzales, N. K. Sauter, and R. P. Phizackerley, "Blu-Ice and the Distributed Control System: software for data acquisition and instrument control at macromolecular crystallography beamlines", J. Synchrotron Radiation, vol. 9, no. 401, 2002.
[10] R. Abbasi, M. Ackermann, J. Adams, J. Ahlers, K. Andeen, J. Auftenberg, X. Bai, M. Baker, and S. Barwick, Nuclear Instr. Methods Phys. Res. Sect. A: Accelerators, Spectrometers, Detectors and Associated Equipment, vol. 601, 294, 2009.

[11] M. Yantidewi, M. S. Muntini, and N. A. Lestari, "The design of a PCbased real-time system for monitoring Methane and Oxygen concentration in biogas production", J. Phys.: Conf. Ser., vol. 997, no. 1, 2018.

[12] N. Nagara and P. I. Yazid, "Pengendali Intensitas Lampu Ruangan Berbasis Arduino UNO Menggunakan Metode Fuzzy Logic", J. Oto. Ktrl. Inst. (J. Auto. Ctrl. Inst), vol. 4, no. 1, p. 17, 2015.

[13] M. A. Sihombing, A. A. Harmawan, and T. N. Manik, J. Fisi. Flux., vol. 14 , no. 1 , p. 53,2017 